\title{
Antinuclear antibodies in patients with Raynaud's phenomenon: clinical significance of anticentromere antibodies
}

\author{
C. G. M. KALlENBERG, G. W. PASTOOR, A. A. WOUdA, AND T. H. ThE \\ From the Department of Clinical Immunology and Cardiology, University Hospital, Groningen, The \\ Netherlands
}

SUMmARY Antinuclear antibodies (ANA) were detected in the sera of 73 out of 138 patients $(53 \%)$ referred to us because of Raynaud's phenomenon. When ANA were found, systemic manifestations were likely to be present. The use of human fibroblast monolayers as a nuclear substrate allowed differentiation of several fluorescence patterns, including the discrete speckled variety produced by anticentromere antibodies. These antibodies were detected in the sera of 7 out of 10 patients with CRST syndrome ( $70 \%)$, in 7 out of 40 patients with scleroderma (18\%), all without kidney-involvement, in one patient with Sjögren's syndrome and severe Raynaud's phenomenon, and in 7 patients with Raynaud's phenomenon associated with a few symptoms of a connective tissue disease (especially scleroderma). ANA testing on tissue culture monolayers in Raynaud's phenomenon appears to be of value in predicting systemic disease manifestations and the presence or possible future development of distinct clinical patterns, especially the CRST syndrome.

Raynaud's phenomenon is characterised by attacks of digital pallor on exposure to cold or emotional stimuli, followed by cyanosis, while painful reddening of the fingers occurs on warming. The phenomenon may precede the development of a connective tissue disease, especially scleroderma, by many years, ${ }^{1}$ although at the first presentation of cases we have often found asymptomatic systemic disease already present. ${ }^{2}$ We have shown ${ }^{2}$ that the presence of antinuclear antibodies (ANA) in patients presenting with Raynaud's phenomenon may predict the presence of systemic disease. Moreover, the titre of the autoantibodies correlated with the number of organ systems affected.

Recently a new type of ANA, directed against the centromere region of chromosomes, has been described.$^{3}$ These antibodies were found especially in patients with the CRST syndrome, a variant of scleroderma characterised by calcinosis, Raynaud's phenomenon, sclerodactyly, and telangiectasia. ${ }^{45}$ Since Raynaud's phenomenon is often an early manifestation of scleroderma and especially of the CRST

\section{Accepted for publication 18 August 1981.}

Correspondence to C. G. M. Kallenberg, MD, Department of Clinical Immunology, Internal Medicine, University Hospital, Oostersingel 59, 9713 EZ Groningen, The Netherlands. syndrome, screening patients with Raynaud's phenomenon for anticentromere antibodies could be of value in establishing the presence or predicting the development of a specific disease like the CRST syndrome. In the present study we tested 138 patients, referred to us because of Raynaud's phenomenon, for the presence of antinuclear antibodies and for signs and symptoms of a connective tissue disease. We also assessed the diagnostic significance of the antigenic specificities of the autoantibodies. In addition we describe the clinical spectrum of 22 patients with antinuclear antibodies directed against the centromere region of chromosomes.

\section{Materials and methods}

\section{S U B J E C T S}

One hundred and thirty eight patients ( 91 female and 47 male) with a diagnosis of Raynaud's phenomenon were studied. All patients were referred by their physicians to the department of vascular diseases because of the clinical severity of the phenomenon. The diagnosis of Raynaud's phenomenon was based on a typical history and on abnormal plethysmographic patterns during cold provocation and/or 
warming-up. ${ }^{6}$ The severity of Raynaud's phenomenon was graded 0 to 5 on cooling and warming. Excluded from this study were patients using drugs known to provoke the phenomenon and patients with large-vessel obstructive arterial disease, a history of trauma to the vessels, a thoracic outlet syndrome, or a carpal tunnel syndrome. In all patients a careful history was obtained and a physical examination was performed. In addition routine laboratory studies, chest roentgenogram, $x$-ray studies of the hands, and an electrocardiogram were performed in all cases. Pulmonary function studies, including diffusing capacity (TLCo), and barium swallow studies of the oesophagus in the horizontal position were done in most cases. When indicated, other investigations, including biopsies, were carried out. In all patients blood was taken for determination of serum antinuclear antibodies, rheumatoid factors, perinuclear factor, and levels of immunoglobulins.

\section{IAGNOSTIC CRITERIA}

A diagnosis of systemic lupus erythematosus (SLE) and rheumatoid arthritis (RA) was based on the diagnostic criteria of the American Rheumatism Association for both diseases. Mixed connective tissue disease (MCTD) was diagnosed on the presence of symptoms as described by Sharp et al. ${ }^{7}$ in combination with the presence of serum antibody to an RNase-sensitive extractable nuclear antigen (ENA). A diagnosis of dermatomyositis was based on the criteria as described by Bohan et al. ${ }^{\circ}$ Sjögren's syndrome was diagnosed when parotid enlargement, xerostomia, and xerophthalmia were present. A diagnosis of scleroderma was made according to the preliminary criteria of the American Rheumatism Association for the disease.$^{9} \mathrm{CRST}$ was considered to be present when all of the syndrome's symptoms (calcinosis, Raynaud's phenomenon, sclerodactyly, telangiectasia) were present. If not accompanied by signs or symptoms of a connective tissue disease (CTD), Raynaud's phenomenon was considered 'primary'. The phenomenon was designated as 'suspected secondary' when a patient had one or more symptoms of a CTD without fulfilling the criteria for a specific CTD.

\section{IMMUNOLOGICAL STUDIES}

Antinuclear antibodies (ANA) were detected by indirect immunofluorescence with human fetal fibroblast monolayers as a substrate. ${ }^{10} \mathrm{~A}$ serum was considered ANA-positive when still positive at a dilution of $1: 100$. The pattern of fluorescence (homogeneous, nucleolar, diffuse granular, discrete finely speckled, or rim) was read by 2 independent observers. Titres of ANA were expressed as logarithms of 10 -fold serum dilutions, 1:10 being taken as 1 .

Antibodies to extractable nuclear antigens were determined by counterimmunoelectrophoresis against a soluble rabbit thymus extract (Pel Freeze Biologicals, Rogers, Arkansas), according to Kurata and Tan. ${ }^{11}$ By RNase digestion of the extract and by using reference sera of aRNP and aSM antibodies (kindly provided by DrE M Tan) the antigenic specificity of the antibodies (directed against RNP, Sm, or other nuclear antigens (o)) was determined. Antibodies to double-stranded or native DNA (adsDNA) were detected by indirect immunofluorescence with the kinetoplast of Crithidia luciliae as a substrate. ${ }^{12}$ Anticentromere antibodies were detected by indirect immunofluorescence on chromosomal spreads of HEp-2 cells as a substrate. ${ }^{3}$ Briefly, HEp-2 cells were cultured in tissue culture medium, supplemented with $10 \%$ newborn calf serum. The cells were then treated with vinblastin $(5 \mu \mathrm{g} / \mathrm{ml})$ for 4 hours and harvested. After washing in RPMI (Roswell Park Memorial Institute) 1640 medium the cells were incubated in $0.075 \mathrm{M}$ $\mathrm{KCl}$ at $37^{\circ} \mathrm{C}$ for $10 \mathrm{~min}$, centrifuged, and sedimented on to slides by cytocentrifugation. Slides were fixed in ice cooled ethanol for $10 \mathrm{~min}$. The slides were used for demonstrating anticentromere antibodies by indirect immunofluorescence. The chromosomes were counterstained with $10 \mu \mathrm{g} / \mathrm{ml}$ of ethidium bromide for $5 \mathrm{~min}$.

\section{Results}

In 138 patients, 47 male and 91 female, a diagnosis of Raynaud's phenomenon was established. According to the diagnostic criteria described above 76 patients $(55 \%)$ could be classified as having a connective tissue disease, the majority having scleroderma (40 patients with scleroderma, 10 patients with CRST syndrome) (Table 1). These 76 patients were considered to have secondary Raynaud's phenomenon. In 62 patients $(45 \%)$ no specific diagnosis could be made, although 24 had one or more symptoms of a systemic disease (Table 1). These were designated as patients with 'suspected secondary' Raynaud's phenomenon. The phenomenon was more severe in patients with CRST and MCTD (Table 1).

Antinuclear antibodies (ANA) in significant titre were present in $53 \%$ of the patients. In patients with primary Raynaud's phenomenon only 6 out of 38 $(16 \%)$ had ANA. In contrast 17 out of 24 patients ( $71 \%$ ) with Raynaud's accompanied by symptom(s) of systemic disease (suspected secondary phenomenon) were ANA-positive. ANA were detected in 21 out of 40 patients $(53 \%)$ with scleroderma and in 7 out of 10 patients with CRST syndrome. All patients 
Table 1 Diagnosis, sex, age, and severity of Raynaud's phenomenon in 138 patients

\begin{tabular}{|c|c|c|c|c|c|}
\hline \multirow[t]{2}{*}{ Diagnosis* } & \multirow[t]{2}{*}{$\begin{array}{l}\text { Patients } \\
\text { (no.) }\end{array}$} & \multirow[t]{2}{*}{$\begin{array}{l}\text { Male/female } \\
\text { (no.) }\end{array}$} & \multirow[t]{2}{*}{$\begin{array}{l}\text { Age } \\
\text { (mean and range, yr) }\end{array}$} & \multicolumn{2}{|c|}{$\begin{array}{l}\text { Severity of Raynaud's } \\
\text { phenomenon (mean) }\end{array}$} \\
\hline & & & & on cooling & on warming \\
\hline $\begin{array}{l}\text { Primary Raynaud's phenomenon } \\
\text { Suspected secondary }\end{array}$ & 38 & $16 / 22$ & $43 \cdot 6(23-68)$ & 1.6 & $1 \cdot 5$ \\
\hline Raynaud's phenomenon & 24 & $6 / 18$ & $46 \cdot 6(17-72)$ & $2 \cdot 2$ & $1 \cdot 5$ \\
\hline Scleroderma & 40 & $16 / 24$ & $47 \cdot 8(22-69)$ & $2 \cdot 4$ & $2 \cdot 2$ \\
\hline MCTD & 10 & $4 / 6$ & $37 \cdot 1(16-66)$ & $3 \cdot 0$ & $3 \cdot 6$ \\
\hline SLE & 7 & $4 / 3$ & $43.9(25-62)$ & $2 \cdot 3$ & $2 \cdot 4$ \\
\hline $\mathbf{R A}$ & 3 & $1 / 2$ & $52 \cdot 0(48-60)$ & $2 \cdot 0$ & $3 \cdot 0$ \\
\hline Dermatomyositis & 3 & -13 & $45 \cdot 7(29-67)$ & $2 \cdot 7$ & $2 \cdot 7$ \\
\hline Sjögren's syndrome & 3 & -13 & $55 \cdot 0(50-60)$ & $2 \cdot 5$ & $3 \cdot 5$ \\
\hline Totals & 138 & $47 / 91$ & & & \\
\hline
\end{tabular}

"MCTD = mixed connective tissue disease; SLE=systemic lupus erythematosus; RA=rheumatoid arthritis; CRST=calcinosis, Raynaud's, sclerodactyly, telangiectasia.

+As measured by photoelectric plethysmography (graded 0 to 5).

with MCTD and SLE and 5 out of the 9 patients with other connective tissue diseases were ANA-positive (Table 2). In general, titres of ANA were higher in patients with Raynaud's phenomenon as part of a connective tissue disease than in patients with isolated Raynaud's (Table 2).

By using fibroblast monolayers as a nuclear substrate fluorescence patterns of ANA were easily detected (Fig. 1). A nucleolar pattern on a homogeneous background (Fig. 1) was found in 4 patients with scleroderma and in 2 patients with primary and suspected secondary Raynaud's phenomenon respectively. This pattern, however, was not a sensitive indicator of scleroderma. The homogeneous pattern (Fig. 1), found in 5 out of 7 patients with SLE (4 of them with antinative DNA antibodies), was not specific for this disease (Table 2 ). The speckled pattern of staining of fibroblast nuclei could be divided into a diffuse granular pattern sparing nucleoli and a discrete finely speckled variety
(Fig. 1). The diffuse granular appearance was seen in all patients with MCTD, but was also seen in some patients with other CTD; in 15 out of 29 patients this pattern was produced by antibodies against extractable nuclear antigens detected by counterimmunoelectrophoresis (Table 2).

When chromosomal spreads of HEp-2 cells arrested in metaphase were used as substrate, it was found that the antibodies responsible for the discrete speckled pattern on fibroblast monolayers were directed against the centromere region of chromosomes (Fig. 2). These anticentromere antibodies were found in all ANA-positive patients with CRST syndrome ( 7 out of 10 ), and also in 7 patients with scleroderma without calcinosis, in 7 patients with suspected secondary Raynaud's phenomenon, and in one patient with Sjögren's syndrome. The clinical characteristics of these 22 patients are given in Table 3 . These patients were especially characterised by the presence of Raynaud's phenomenon (100\%),

Table 2 Diversity of antinuclear antibodies in patients with Raynaud's phenomenon

\begin{tabular}{|c|c|c|c|c|c|c|c|c|c|c|c|c|c|}
\hline Diagnosis* & $\begin{array}{l}\text { Patients } \\
\text { (no.) }\end{array}$ & $\begin{array}{l}\text { ANA-positive } \\
\text { patients } \ddagger \\
\text { (no.) }\end{array}$ & $\begin{array}{l}\text { Titre of } \\
\text { ANA (mean } \\
\text { and range) }\end{array}$ & \multicolumn{5}{|c|}{$\begin{array}{l}\text { Fluorescence } \\
\text { pattern of ANA }(\text { (no.) }\end{array}$} & \multicolumn{3}{|c|}{$\begin{array}{l}\text { ENA-positive } \\
\text { patients (no.) }\end{array}$} & $\begin{array}{l}\text { Patients with } \\
\text { anticentromere } \\
\text { antibodies (no.) }\end{array}$ & $\begin{array}{l}\text { Patients } \\
\text { with a-ds } \\
\text { DNA (no.) }\end{array}$ \\
\hline \multicolumn{14}{|l|}{ Primary Raynaud's } \\
\hline $\begin{array}{l}\text { phen. } \\
\text { Suspected secondary }\end{array}$ & 38 & $6(16 \%)$ & $2 \cdot 33(2-3)$ & 1 & 2 & 3 & - & - & - & - & - & - & - \\
\hline Raynaud's phen. & 24 & $17(71 \%)$ & $3.06(2-6)$ & 1 & 5 & 4 & 7 & - & - & - & - & 7 & - \\
\hline Scleroderma & 40 & $21(53 \%)$ & $3.59(2-6)$ & 4 & 1 & 8 & 7 & 1 & - & 1 & - & 7 & 1 \\
\hline CRST & 10 & $7(70 \%)$ & $4 \cdot 4 \quad(3-6)$ & - & - & - & 7 & - & - & - & - & 7 & - \\
\hline MCTD & 10 & $10(100 \%)$ & $5 \cdot 4(3-6)$ & - & - & 10 & - & 一 & 10 & - & - & - & - \\
\hline SLE & 7 & $7(100 \%)$ & $5 \cdot 2 \quad(3-6)$ & - & 5 & 2 & - & - & 1 & 1 & - & - & 4 \\
\hline Otherst & 9 & $5(55 \%)$ & $4 \cdot 2 \quad(4-5)$ & - & 2 & 2 & 1 & - & - & - & 1 & 1 & - \\
\hline Totals & 138 & $73(53 \%)$ & & 6 & 15 & 29 & 22 & 1 & 12 & 2 & 1 & 22 & 5 \\
\hline
\end{tabular}

*CRST = calcinosis, Raynaud's, sclerodactyly, telangiectasia; MCTD=mixed connective tissue disease; SLE=systemic lupus erythematosus. trheumatoid arthritis (3), dermatomyositis (3), Sjögren's syndrome (3). $\ddagger$ ANA-positive when titre $>1: 100$.

$\S \mathrm{H} / \mathrm{N}=$ nucleolar and homogeneous; $\mathrm{H}=$ homogeneous; $\mathrm{Gr}=$ diffuse granular; $\mathrm{Sp}=$ discrete finely speckled; $\mathrm{N}=$ nucleolar. 

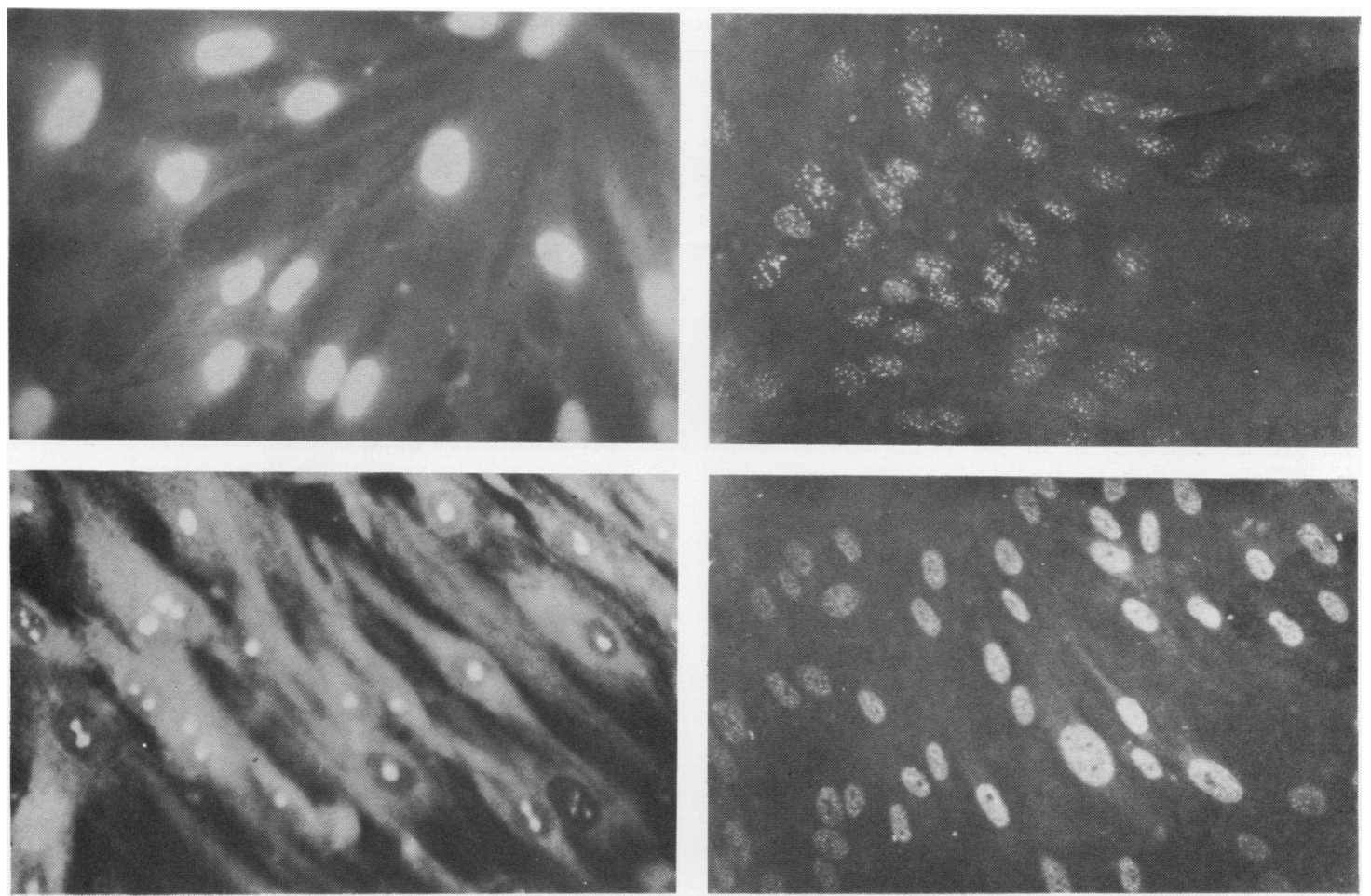

Fig. 1 Immunofluorescence photomicrograph of fibroblast monolayers reacted with ANA-positive serum samples. Homogeneous (upper left). Discrete finely speckled (upper right). Nucleolar (lower left). Diffuse granular with sparing of nucleoli (lower right).

sclerodactyly ( $73 \%)$, telangiectasia (68\%), a history of arthritis or arthralgia (77\%), and loss of pulmonary function (decreased diffusing capacity, $76 \%$ ). Oesophageal hypomotility was present in $45 \%$ of these patients. Other systemic manifestations such as kidney and heart involvement were usually absent. In the 3 patients with CRST without these antibodies no other ANA were detected. The 7 out of 40 scleroderma patients with anticentromere antibodies were especially characterised by sclerodactyly and marked digital scarring but lacked calcinosis. Seven patients with Raynaud's phenomenon and anticentromere antibodies did not fulfil criteria for the diagnosis of a specific CTD. They were clinically characterised by the presence of Raynaud's phenomenon, arthritis or arthralgia, decreased pulmonary diffusing capacity and, to a minor degree, sclerodactyly. None of the patients showed a correlation between titre of anticentromere antibodies and severity of the clinical syndrome.

\section{Discussion}

Raynaud's phenomenon is associated with connective tissue diseases, especially scleroderma. In the latter (micro)vascular lesions are thought to be involved in the pathogenesis of the lesions in the affected organs. ${ }^{13}$ Vascular changes are often not restricted to the fingers, but are probably involved in the systemic manifestations found in many patients presenting with the phenomenon. ${ }^{2}$ This was also suggested by the observation that the severity of Raynaud's phenomenon correlated positively with the extent of systemic involvement. In the present study we again found increasing severity when comparing patients with primary Raynaud's phenomenon, patients with a suspected secondary phenomenon, and patients with the phenomenon as part of a connective tissue disease.

Like scleroderma, ${ }^{13}$ Raynaud's phenomenon is associated with immunological disturbances. Even in patients with primary phenomenon decreased invitro cellular immunity and increased levels of phagocytosed immune complexes were observed. ${ }^{10}$ In addition we demonstrated that the diversity of autoantibodies and the titre of antinuclear antibodies in the serum of a patient with Raynaud's phenomenon both correlate positively with the number of affected organ systems. ${ }^{2}$ The pathogenetic relation 
Table 3 Clinical characteristics of 22 patients with anticentromere antibodies

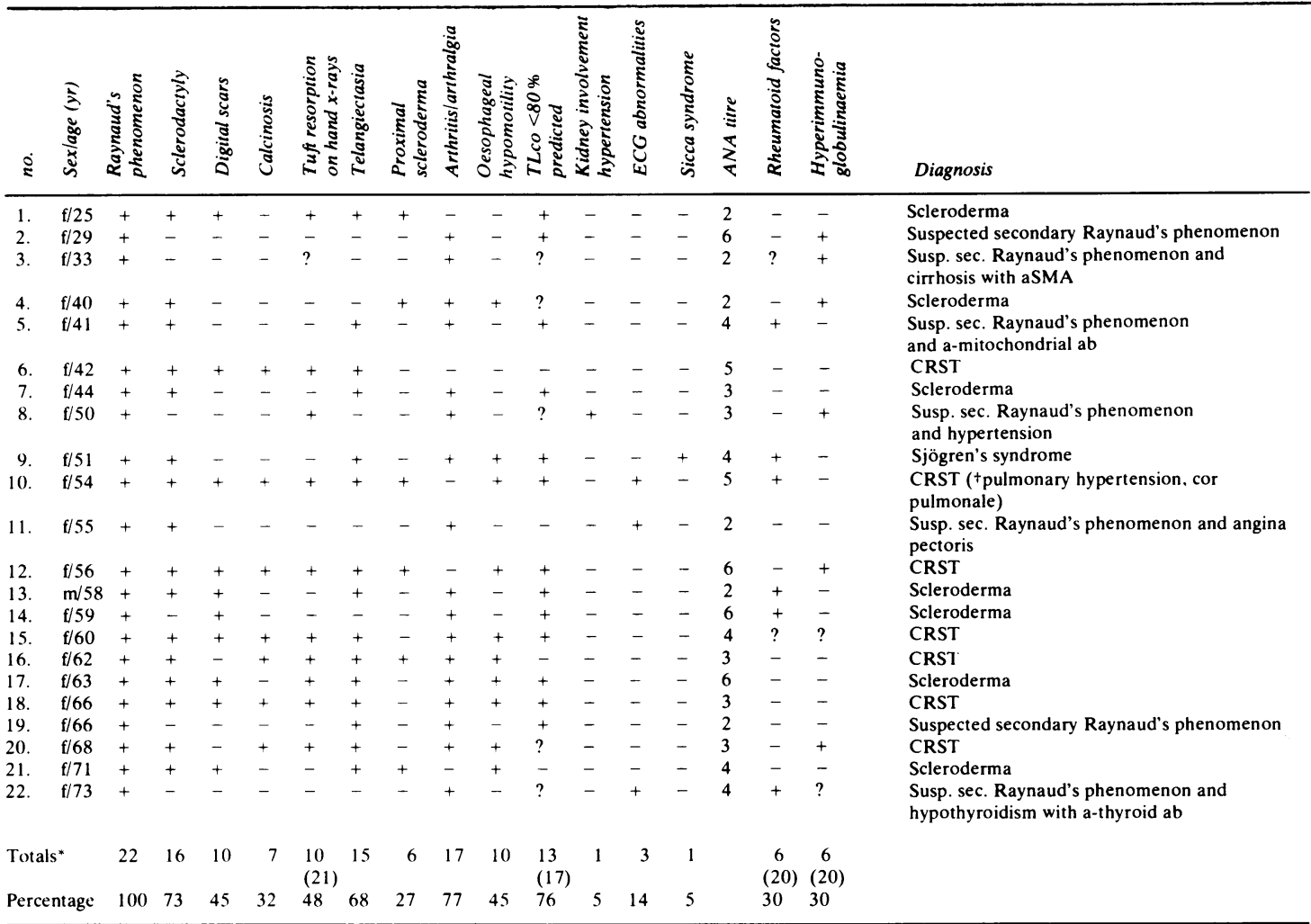

${ }^{*}$ Number of patients studied in parentheses.

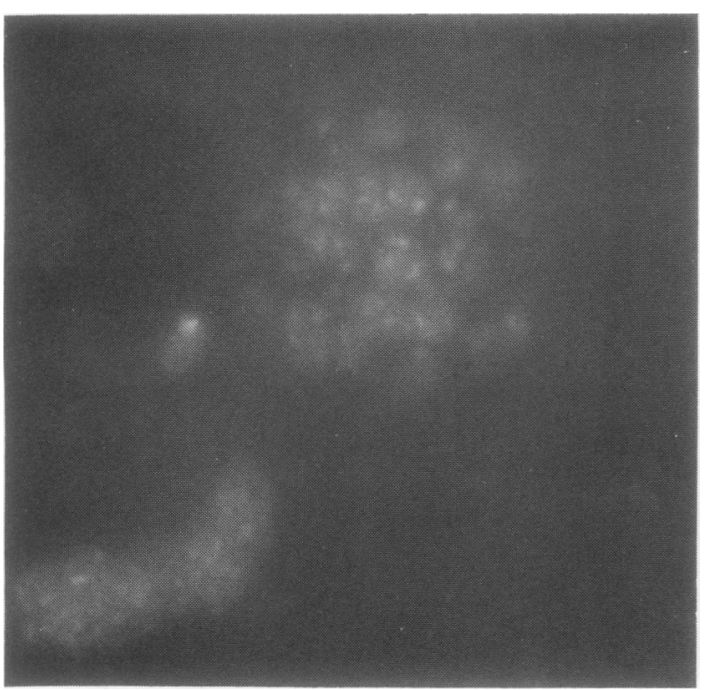

Fig. 2 Immunofluorescence photomicrograph of HEp-2 cells, arrested in metaphase, reacted with serum positive for centromere antibodies. The chromosomes are counterstained with ethidium bromide. between these immunological aberrations and the supposed microvascular disease is not clear.

In the present study the clinical significance of antinuclear antibodies in Raynaud's phenomenon was further evaluated. Firstly, when ANA were detected in the serum of a patient, systemic manifestations were likely to be present. Thus of all the patients with ANA only 6 had primary Raynaud's, whereas 67 had Raynaud's phenomenon associated with systemic disease. Secondly, the fluorescence pattern of ANA proved important. By using fibroblast monolayers as a nuclear substrate for detection of ANA, fluorescence patterns could be readily differentiated. This applied especially to the discrete finely speckled pattern produced by sera with anticentromere antibodies, which were clearly detectable on this substrate. These sera were usually ANAnegative when rat liver sections were used as a substrate. ${ }^{14}$. As to the other patterns, nucleolar fluorescence produced by antibodies against nucleolar 4-6 S RNA $^{15}$ and often seen against a positive homogeneous background was in general restricted to scleroderma, although not a sensitive indicator of this disease. The homogeneous pattern was often found 
in patients with SLE but was also observed in other conditions. The speckled pattern could be divided into a diffuse granular pattern with sparing of nucleoli, and a discrete finely speckled pattern, which was exclusively produced by anticentromere antibodies.

Anticentromere antibodies were recently described by Tan, ${ }^{4}$ in 12 out of 21 patients with CRST syndrome $(57 \%)$ and in 2 out of 24 with scleroderma ( $8 \%$ ), and by Fritzler et al.,${ }^{5}$ in 26 out of 27 patients with CRST $(96 \%)$ and in 3 out of 26 with scleroderma $(12 \%)$. In our study patients were selected for the presence of Raynaud's phenomenon. Since the phenomenon often precedes development of scleroderma or CRST, one might have expected to find patients with early CRST or scleroderma in our group. Like other authors we found the antibodies in 7 out of 10 patients with CRST syndrome (70\%). In the 3 patients with CRST who lacked these antibodies no other specificities of ANA were found. Since only a titre of ANA $\geqslant 1: 100$ was considered as positive, anticentromere antibodies could have been present in these 3 patients in lower titre. In addition 7 out of 40 patients with scleroderma $(18 \%)$ had anticentromere antibodies. Clinically these patients had sclerodactyly, Raynaud's phenomenon, and telangiectasia, with proximal scleroderma restricted to the face. But they lacked calcinosis and involvement of heart and kidneys. Finally, these antibodies were detected in 7 out of 24 patients with Raynaud's phenomenon associated with symptoms or signs of a connective tissue disease. In this group of patients sclerodactyly, arthritis or arthralgia, telangiectasia, and pulmonary function disturbances were frequently present, and they may represent an early stage of CRST or scleroderma. Follow-up studies will thus demonstrate the predictive value of anticentromere antibodies.

Although anticentromere antibodies seem to be a marker of the CRST syndrome and might have a predictive value as to its development, their pathogenetic significance is not clear. Further studies may show whether they are involved in the pathogenesis of the chromosomal abnormalities which are described in scleroderma. ${ }^{16}$ Whatever their pathogenetic significance, antinuclear antibodies in patients with Raynaud's phenomenon are an important indicator of underlying systemic disease.
This study was supported by a grant from Het Praeventiefonds.

\section{References}

${ }^{1}$ Bennett R, Bluestone R, Holt P J L, et al. Survival in scleroderma. Ann Rheum Dis 1971; 30: 581-8.

${ }^{2}$ Kallenberg C G M, Wouda A A, The T H. Systemic involvement and immunologic findings in patients presenting with Raynaud's phenomenon. Am J Med 1980; 69: 675-80.

${ }^{3}$ Moroi Y, Peebles C, Fritzler J, Steigerwald J, Tan E M. Autoantibody to centromere (kinetochore) in scleroderma sera. Proc Natl Acad Sci USA 1980; 77: 1627-31.

4 Tan E M, Rodnan G P, Garcia I, et al. Diversity of antinuclear antibodies in progressive systemic sclerosis. Anticentromere antibodies and their relationship to CREST-syndrome. Arthritis Rheum 1980; 23: 617-25.

${ }^{5}$ Fritzler M J, Kinsella T D, Garbutt E. The CREST-syndrome: a distinct serologic entity with anticentromere antibodies. Am J Med 1980; 69: 520-6.

- Wouda A A,. Raynaud's phenomenon. Photoelectric plethysmography of the fingers of persons with and without Raynaud's phenomenon during cooling and warming up. Acta Med Scand 1977; 201: 519-23.

' Sharp G C, Irving W S, May C M, et al. Association of antibodies to ribonucleoprotein and $\mathrm{Sm}$ antigens with mixed connective tissue disease, systemic lupus erythematosus and other rheumatic diseases. N Engl J Med 1976; 295: 1149-54.

${ }^{8}$ Bohan A, Peter J B, Bowman R L, Pearson C M. A computerassisted analysis of 153 patients with polymyositis and dermatomyositis. Medicine 1977: 56: 255-86.

- Masi A T, Rodnan G P, Medsger Th A, et al. Preliminary criteria for the classification of systemic sclerosis (scleroderma). Arthritis Rheum 1980; 23: 581-90.

${ }^{10}$ Meulen van der J. Immunological studies in Raynaud's phenomenon. Academic thesis. Groningen, the Netherlands, 1979.

${ }^{11}$ Kurata N, Tan E M. Identification of antibodies to nuclear acidic antigens by counterimmunoelectrophoresis. Arthritis Rheum 1976; 19: 574-80.

12 Aarden L A, de Groot E R, Feltkamp T E W. Immunology of DNA III. Crithidia luciliae, a simple substrate for the determination of anti-ds DNA with the immunofluorescence technique. Ann NY Acad Sci 1975; 254: 505-15.

${ }^{13}$ Rodnan G P. Progressive systemic sclerosis (scleroderma). In: Samter M, ed. Immunological Diseases. Boston: Little, Brown, 1978: $1109-41$.

${ }^{14}$ Kallenberg C G M, Meulen van der J, Pastoor G, Snijder J A M, The T H, Feltkamp T E W. Human fibroblasts, a convenient nuclear substrate for detection of antinuclear antibodies including anticentromere antibodies. Submitted for publication.

15 Pinnas J L, Northway J D, Tan E M. Antinuclear antibodies in human sera. J Immunol 1973; 111: 996-1004.

${ }^{16}$ Pan S F, Rodnan G P, Wald N. Chromosomal abnormalities in progressive systemic sclerosis (scleroderma). Arthritis Rheum 1971 ; 14: 407-8. 